\title{
LA ACTUACIÓN CONTRA EL EXPOLIO DEL PATRIMONIO ARQUEOLÓGICO EN ANDALUCÍA
}

\section{POLICY AGAINST THE LOOTING OF ANDALUSIAN ARCHAEOLOGICAL SITES}

por

\author{
IGNACIO RODRÍGUEZ TEMIÑO
}

RESUMEN Este artículo trata sobre el expolio producido por los aparatos de detección de metales en los yacimientos arqueológicos. En él se hace especial hincapié en las medidas jurídicas y administrativas adoptadas por la Junta de Andalucía para luchar contra esta plaga que amenaza con destruir una parte importante de nuestro patrimonio arqueológico.

\begin{abstract}
This article deals with the pillage produced by metal detectors in archaeological sites. Special emphasis is placed on the legal and administrative steps taken by the Junta de Andalucía against this plague which threatens to destroy an important part of our archaeological heritage.
\end{abstract}

\section{INTRODUCCIÓN}

El expolio, especialmente en el sentido amplio que el legislador ha dado a este término, como pérdida, destrucción o impedimento para cumplir la función a que están llamados los bienes culturales (art. 4 de la Ley 16/1985, de Patrimonio Histórico Español, corroborado por la sentencia del Tribunal Constitucional 17/1991), constituye sin lugar a dudas una de las externalidades más graves y preocupantes entre las que actúan sobre el patrimonio histórico de carácter arqueológico, hasta el punto de constituir la lucha contra el mismo un campo de concurrencia competencial entre todas las administraciones públicas, según razona la citada sentencia en sus fundamentos jurídicos $3^{\circ}$ y $7^{\circ}$.

Sin embargo, a pesar de este reconocimiento, la lucha contra el expolio arqueológico no se ha materializado en una de las políticas más desarrolladas por las administraciones culturales. Carencia que afecta no sólo al Estado español, sino a todo el ámbito europeo, si bien es notoriamente conocido que esta lacra se ceba especialmente en los países del entorno mediterráneo, donde han surgido civilizaciones con gran esplendor 
en sus manifestaciones artísticas y artesanales. Las causas de la falta de control en muchas de las actividades que podrían denominarse expoliadoras son variadas, pero en general, aunque con notables variaciones entre países ricos y pobres, se reducen a la nefasta combinación de una legislación poco adecuada y a la falta de recursos humanos y medios económicos y técnicos suficientes para llevar a cabo una labor de salvaguarda eficaz, de un lado, junto al estado embrionario de las políticas preventivas de difusión y promoción para encauzar una protección activa, apoyada en el aumento del nivel educativo de la población de muchos de estos países, que incida positivamente en la raíz del problema.

Antes de proseguir, me parece necesario hacer ciertas consideraciones en torno al expolio del patrimonio arqueológico con objeto de centrar el tema de esta exposición. Posteriormente pasaré al análisis de la situación actual en la comunidad autónoma de Andalucía, por ser de donde tengo mayor información.

En primer lugar, es preciso aclarar que, en aras de la concisión, restrinjo la amplitud antes mencionada del término expolio a la de realización de remociones de tierra clandestinas, normalmente asociadas al uso de detectores de metal, en busca de objetos antiguos destinados al coleccionismo particular. Este tema resulta ser uno de los aspectos de la protección del patrimonio arqueológico menos considerados, a pesar de haberse convertido en la amenaza más extendida debido a la popularización del uso de estas máquinas, y a los pinguies beneficios que lleva aparejado la venta ilegal de piezas arqueológicas.

En segundo lugar, debe indicarse que se desconoce la magnitud del grado de afección que el expolio ha perpetrado al patrimonio arqueológico, como ya señalara L. Caballero (1982: 29) hace más de quince años, sin que desde entonces hasta ahora haya cambiado mucho la situación a este respecto. La opacidad de estos datos surge obviamente de encontrarnos ante una actividad clandestina, carente de todo tipo de control y, por tanto, sin medios precisos para cualquier cuantificación. Sin embargo, habría algunas cifras que sí deberían ser conocidas, aunque fuese de forma aproximada, por las administraciones concernidas. Por ejemplo, se carece de una aproximación fiable del número de yacimientos, no ya "peinados" con detectores de metal, sino objeto de amplios movimientos de tierra con la intención de exhumar estructuras arqueológicas, especialmente tumbas, en las que expoliar los ajuares. Normalmente es a través de inspecciones directas giradas por técnicos o especialistas, tras una denuncia, a tal o cual yacimiento; la visita a un mercadillo o una colección particular; o más comúnmente, con la presentación ante los medios de comunicación de una colección de objetos arqueológicos requisada por las autoridades judiciales o policiales, como puede entreverse la dimensión del daño causado por este fenómeno, siempre en la creencia de que con estos casos sólo asoma la punta del iceberg. Pero poco más que conjeturas se ponen encima de la mesa a este respecto. Algo más podría hacerse. En los últimos tiempos la investigación arqueológica ha conocido un crecimiento exponencial de las actividades de prospección, realizadas ahora de forma sistemática y detenida, y con una estructuración de la información en fichas prediseñadas con objeto de normalizar la recogida de datos. En muchas de esas fichas no existe la más mínima referencia a si se aprecian señales de haber sido expoliado el yacimiento, algo fácil de observar en la mayoría de las ocasiones (Iniesta 1996); en otras, como en las de los inventarios y catálogos al uso en las administraciones, apenas se deja espacio para indicar que ha sido expoliado, pero sin más precisiones en cuanto al área afectada o al volumen de los desmontes. En fin, de haberse tomado en cuenta estos extremos con suficiente consideración, ahora tendríamos un primer inicio de cuantificación, al menos para las grandes áreas geográficas afectadas por el expolio, algo que sólo conocemos de forma intuitiva o en muestras posiblemente no lo suficientemente representativas.

En otro orden de cosas, tan siquiera se tiene idea aproximada del número de detectoristas en cada comunidad autónoma, aunque se sabe de la existencia de asociaciones locales de aficionados a esta labor y de federaciones de éstas a escala regional y estatal, como la asociación Karmo en Carmona (Sevilla), o la Asociación Española de Detectoristas, que además publica (o al menos lo hacía) un boletín denominado El Buscador. Tampoco, que yo sepa, se han usado estas vías para poner en conocimiento de los afiliados a las mismas, las obligaciones legales que conlleva tal práctica con respecto a los bienes integrantes del patrimonio arqueológico, por cuanto 
que el Código ético del detectorista que se entrega al adquirir uno de estos aparatos es claramente insuficiente para estos fines.

En tercer lugar, la desproporción entre la magnitud de la tarea a emprender y la escasez de medios dedicados a ella ha provocado una suerte de tradicional inhibición en las administraciones concernidas, y entre los expertos, que suplen la inactividad con el lamento (lo que L. Caballero denomina en el trabajo citado "pesimismo generalizado en los ambientes arqueológicos") para, seguidamente, dejar de lado el problema por considerarlo insoluble, prefiriendo otros campos más "rentables" en términos de compensación de esfuerzos, relacionados con las actuaciones de policía administrativa y el establecimiento de cautelas para tutelar el patrimonio arqueológico en actividades legales (fundamentalmente obras públicas y privadas).

Por supuesto, existen razones suficientes para justificar el papel de Jeremías desempeñado habitualmente por los arqueólogos. Pero también es cierto que, a fuerza de orillar el problema, paradójicamente se le ha dedicado poca atención, aunque sea en aspectos puntuales; que quienes tienen alguna experiencia en este campo, debido a esta marginación, nunca han considerado relevante transmitirla, o no han encontrado los foros idóneos para hacerlo; que se ha clamado por leyes represoras de las conductas expoliadoras, pero ha faltado reivindicar de la administración campañas educativas de difusión sobre el papel de la arqueología en la sociedad, más allá del aprecio por los objetos antiguos, o de respeto por los monumentos, como se ha hecho en otros países. Italia, con su campaña "Stop al vandalismo gráfico", iniciativa dirigida hacia los más jóvenes para concienciarlos sobre los efectos nocivos de los grafitos en monumentos, o más específicamente la muestra titulada "¡Procedencia desconocida!", presentada en Kassel en 1995 (citada en Fernández Gómez 1996: 285), ofrecen un buen ejemplo a seguir. En España, por el contrario, como veremos más abajo, apenas existe algo comparable a pesar de las innumerables exposiciones que se celebran anualmente relacionadas con la arqueología. Igualmente fue casi nulo el eco que tuvo en medios oficiales y profesionales la Recomendación 921 (1981) de la Asamblea Parlamentaria del Consejo de Europa, relativa a detectores de metales y arqueología (Caballero 1982).

Por último, entre estas consideraciones previas, habría que hacer mención al importante esfuerzo normativo en materia de patrimonio histórico y cultural, realizado por parte de los legisladores autónomos, a partir de la promulgación de la LPHE. De una u otra forma, se ha hecho común en todas estas normas prohibir el uso de detectores de metal en yacimientos arqueológicos. Sin embargo, en ocasiones, la falta de una experiencia previa ha motivado dificultades para ajustar bien la tipificación de las conductas infractoras, dando lugar a problemas de interpretación a la hora de incoar un expediente sancionador por esta causa; o bien, más frecuentemente, estas normas se limitan a redundar en los contenidos ya expresados por la LPHE.

Caso paradigmático de esta última eventualidad es el Decreto 58/1994, de 11 de marzo, de la Consejería de Cultura y Turismo, de normas sobre prospecciones arqueológicas, utilización y publicidad de aparatos detectores de metal, de la Junta de Castilla y León. En la exposición de motivos se justifica la necesidad de esta norma en corregir la pérdida de yacimientos arqueológicos producto de la rebusca de materiales arqueológicos por parte de particulares, actividad agravada por el uso de detectores de metal. La estrategia seguida en el citado Decreto ha sido asimilar la búsqueda de metales con detectores a las prospecciones arqueológicas (artículo 2.b.), actividad sujeta a la autorización de la Consejería, recordando la obligatoriedad de dar parte del cualquier hallazgo a la administración, sin perjuicio de las responsabilidades y sanciones a que diese lugar la práctica de tales actividades sin la debida autorización.

Como se ha señalado en otras ocasiones (Querol y Martínez 1996: 251; Maldonado, inédito), esta norma promete más de lo que se atreve a disponer. Las prospecciones descritas en su artículo 2.b. lo son porque el Decreto lo dice, pero lo seguirían siendo aunque no lo dijese. Si se prueba que un sujeto realiza el examen de un terreno con un detector de metales con la finalidad de buscar objetos susceptibles de ser estudiados arqueológicamente, se trataría de una prospección arqueológica aunque el Decreto no lo señalase expresamente, 
con lo cual su articulado no aporta nada a la problemática que entraña la instrucción de un expediente sancionador. En fin, como acertadamente razona Maldonado, para ese viaje no se precisan alforjas.

Pero quizás lo más llamativo de esta eclosión de normas autonómicas sea la falta de relación entre las nuevas obligaciones impuestas a las administraciones encargadas de ponerlas en práctica y los medios de que disponen para hacerlo. Se da la circunstancia de que, en muy pocas ocasiones, la aparición de una de estas leyes ha tenido como consecuencia la ampliación de los órganos administrativos directamente implicados en velar su cumplimiento. Carencia que habitualmente se encargan de recordar las recomendaciones internacionales y que, en el Estado español, el propio legislador autónomo ha comenzado a poner de manifiesto en el preámbulo de algunas de estas leyes sobre patrimonio histórico y cultural.

Esta falta de medios humanos se traduce especialmente en una descompensación de la actuación administrativa. Habitualmente, se concentra todo el esfuerzo en la producción del acto administrativo (sea informe, resolución u otro cualquiera), pero posteriormente no se lleva a cabo un control eficaz, mediante inspecciones, para asegurar que lo informado o resuelto se materializa en los términos indicados.

Buena muestra de esta falta de contenidos concretos para acometer la lucha contra el expolio, tanto a nivel de experiencias como de indagación o reflexiones, se refleja en la escasez de trabajos publicados sobre este tema, aunque afortunadamente están empezando a ser más normales en los últimos años (Caballero 1982; Benítez de Lugo y Sánchez-Sierra 1995; Querol y Martínez 1996; Fernández Gómez 1996, entre otros). En este sentido, caben destacar, además de contribuciones particulares en artículos, libros o informes administrativos, el curso dedicado a la protección del patrimonio histórico especialmente dirigido a los cuerpos y fuerzas de seguridad del Estado, organizado por la Consejería de Cultura y Educación déla Región de Murcia en 1994 (Curso... 1996) y las Jornadas celebradas en Ávila en 1997, producto de la colaboración entre la Junta de Castilla y León y la Guardia Civil (Jornadas... 1998), que han dejado sendas publicaciones del máximo interés.

No obstante, suele ser frecuente en la mayoría de los trabajos rellenar el espacio repitiendo una y otra vez las disposiciones legales vigentes, tanto en el derecho administrativo como penal, sobre la protección del patrimonio histórico de carácter arqueológico, sin avanzar ni una sola propuesta sobre cómo paliar esta plaga o qué estrategia seguir para controlar determinados aspectos de la misma. Mucho menos explicar qué experiencias han desarrollado las administraciones competentes en este terreno.

En resumen, estamos ante un campo de actuación que viene de antiguo, pero que está prácticamente intacto, incluso en el marco de actuación de las más altas instituciones, como corrobora el contenido dirigido hacia esta problemática concreta (el expolio de yacimientos arqueológicos) incluida en el "Decálogo para la lucha contra el expolio" elaborado por el Ministerio de Educación y Cultura, como conclusión de la reunión del Consejo de Patrimonio Histórico, celebrada en Alcalá de Henares, el 20 de febrero de 1998 ("Se estudiarán medidas concretas y específicas para evitar el expolio en yacimientos arqueológicos tanto terrestres como subacuáticos", Hispania Nostra, 71/72, abril de 1998: 16).

Termino este preámbulo con una primera conclusión: en este estado de cosas resulta utópico pensar que las administraciones culturales puedan ellas solas cumplir y hacer cumplir la ley en esta materia. Esto es, frenar el expolio.

\section{SITUACIÓN ACTUAL EN ANDALUCÍA}

Producto de la poca dedicación dispensada a este tema se han consolidado tópicos que enmascaran una realidad ciertamente más compleja, desconocida y amenazante.

Según mi propia experiencia, iniciada a mitad de los ochenta como arqueólogo municipal en Écija (Sevilla), situada en el corazón de una de las zonas más activas en cuanto al comercio ilícito de piezas arqueológicas 
y al detectorismo se refiere, los hábitos expoliadores han cambiado en los últimos años. Esta circunstancia merece cierto análisis detallado.

La expansión del uso de detectores de metal, introducido en Andalucía por algunos estadounidenses de las bases de utilización conjunta de Rota (Cádiz) y Morón de la Frontera (Sevilla), coincidió con la roturación profunda mediante subsoladores de muchos campos de labor hasta entonces dedicados al cultivo del olivar, lo que facilitó hallazgos monetarios, y metálicos en general, ciertamente espectaculares, así como la entrada en un mercado consolidado, pero aún no saturado, de numerario en aceptable estado de conservación, sentando las bases de un comercio rentable para quienes salían al campo a buscar monedas provistos de tales aparatos. Estas máquinas fueron rápidamente comercializadas por la casa White's, la única que por esas fechas tenía una sucursal radicada en Madrid.

Entre esta primera ola de buscadores se hallaban coleccionistas locales de corte erudito, como V. Durán, autor de un librito sobre la batalla de Munda basado en los hallazgos realizados por él mismo en los yacimientos del entorno de Écija (especialmente un botón de plata con las iniciales de A. Varo, como es sabido general pompeyano muerto en esa batalla, y que, tras ser comprado por el cabildo astigitano -al igual que el resto de su colección- se encuentra actualmente en paradero desconocido, sin que nadie sepa dar razón de qué ha pasado con esa pieza) (Durán 1984). Sus hipótesis y las evidencias que las sustentaban fueron bien recibidas en el ámbito universitario y, posteriormente, con la indispensable ayuda de un especialista en la época, reelaboró este trabajo en un tono más acorde con los usos científicos, depurándolo de toda la hojarasca erudita presente en la primera edición (Durán y Ferreiro 1984). Estos coleccionistas locales, normalmente, no solían vender piezas, salvo en casos de apuro económico severo. Junto a ellos, aparecerán los aficionados, con niveles socioeconómicos más bajos, que no buscaban tanto la colección privada propia como el ánimo de lucro, abierto por las expectativas comerciales del negocio numismático.

Con el tiempo éstos terminarán por desplazar a aquéllos, que pasaron a ser meros espectadores del nuevo proceso que se estaba desarrollando. Efectivamente, la afluencia de anticuarios, coleccionistas e instituciones museísticas, nacionales y extranjeros, determinó la conversión de algunos de estos aficionados en intermediarios de comercio ilegal de objetos antiguos que, como al apodado "El barbero de La Lantejuela" o al también barbero y propietario del bar El Denario, de Écija, les supuso un aceptable cambio a mejor en su nivel de vida (actualmente este bar ha cambiado de dueño y nombre). Las noticias de auténticos "pelotazos" animó a muchas personas a lanzarse al campo en busca de monedas y otros objetos metálicos antiguos. Obviamente, no puedo si quiera sugerir un número aproximado de cuántos empezaron esta aventura. Habitualmente se habla de miles de personas, asociándolo al paro agrícola. Bien, aunque sea indudable la relación entre ambos fenómenos, esas cifras, publicadas frecuentemente en los medios de comunicación, me parecen una exageración. Como dato puedo señalar que a mitad de los ochenta en Écija había una docena corta de buscadores clandestinos en activo; me cuesta pensar que algunos años antes hubiese muchos más.

Esta edad de oro duró poco. La puesta en cultivo de esas tierras trajo aparejada el abono de las mismas con productos nitrogenados y fosfatados, que atacan el metal eliminando la pátina y corroyendo la pieza. Amén de ello, el mercado se inflacionó de piezas con la consiguiente bajada de los precios. De hecho, actualmente en los mercadillos callejeros la inmensa mayoría del numerario se vende al peso, razón por la cual las monedas no se limpian ni clasifican, y se exponen junto a otros objetos metálicos indeterminados.

Esta caída de los objetos auténticos ha inducido varios cambios para reajustar la actividad del detectorista y el negocio de la venta de antigüedades al nuevo escenario. De una parte, ha animado la entrada de imitaciones en el mercado, provocando incertidumbre en compradores poco expertos. Con bastante más repercusiones para nuestro interés, también ha sido la causa de la expansión de la esfera de influencia de los detectoristas a otras zonas de Andalucía como la vega antequerana, Ronda y las campiñas jiennenses, conformándose así un triángulo, circunscrito más o menos al valle del Guadalquivir, con inclusión de algunas vegas periféricas y zonas de costa, donde se produce la inmensa mayoría de esta modalidad de expolio arqueológico terrestre. 
La ampliación de la actividad depredatoria ocasionó, a su vez, una doble reestructuración. En primer lugar, aparecen las redes de buscadores, que viajan en grupos de tres o cuatro personas, trabajan a destajo y comparten a medias las ganancias. Además, las máquinas usadas no tienen por qué pertenecerles, es frecuente el alquiler o la compra a plazos a los intermediarios, que reciben a cambio la exclusividad en manejar el producto de la rapiña, descontando el pago del plazo de la compra o el alquiler en especies. Al menos esto se deduce de algunas intervenciones del SEPRONA en que el propietario de las máquinas intervenidas no estaba entre los buscadores.

En segundo lugar, se produce un nuevo reajuste: ante el deterioro irreversible de los objeto metálicos no nobles, el expolio se extiende a objetos antiguos de todo tipo (esculturas de piedra, cerámica, vasos de vidrio, etcétera), que tienen igualmente cabida en el mundo del coleccionismo anticuarista. Para este menester se usan también los detectores de metal. Efectivamente la señal sonora emitida por estos aparatos se apaga cuando pasa sobre una estructura de fábrica. Una diestra batida permite averiguar si la estructura enterrada se trata de una tumba o un muro de vivienda. Evidentemente para este tipo de trabajos un aparato medianamente bueno profundiza bastante más que cuando se trata de localizar una moneda, cuya masa es infinitamente menor. Una vez encontrada una tumba, en pocas horas levantan una necrópolis entera, normalmente por la noche a la luz de los faros de un vehículo, estableciendo un turno rotativo de descanso.

Sánchez Arroyo (1998: 143 s.) ha establecido una división similar a la que planteo aquí, pero no de carácter progresivo en el tiempo, sino como diversas facetas del modus operandi de los expoliadores, lo que también responde a la realidad.

Podría resumir señalando que hoy día son menos quienes se dedican a salir al campo en busca de objetos metálicos o de otro tipo, e incluso ya no lo hacen con la frecuencia, casi diaria, de hace veinte o veinticinco años, pero a cambio quienes lo hacen están mejor organizados y tienen más movilidad, con lo cual el destrozo que producen es significativamente mayor.

Recientemente, la Dirección General de la Guardia Civil ha mostrado en diversas ocasiones (por ejemplo, en la reunión del Consejo de Patrimonio Histórico antes mencionada) una estadística sobre las actuaciones del SEPRONA en esta materia, en la que aparece Andalucía como la comunidad donde se produce aproximadamente el 70\% del expolio dentro del Estado (Sánchez Arroyo 1998: 142). Bien, ya se ha visto que Andalucía es un lugar preferente para la comisión de estos actos ilícitos, pero semejante desproporción es más que cuestionable. Para empezar la estadística enumera las denuncias realizadas por dicho servicio y no todo los expolios cometidos en los yacimientos; o sea que los datos expuestos dependen en alto grado de un cúmulo indefinido de variables humanas, imposibles de precisar y evaluar, como puede ser la mayor sensibilidad hacia esta problemática entre sus miembros. A este respecto, debe tomarse en cuenta que en fecha tan temprana como 1986, el Gobierno Civil de Sevilla emitía la circular número 2, de ese año, publicada en el Boletín Oficial de la Provincia, de 5 de mayo, en la que se advertía a los cuerpos y fuerzas de seguridad sobre "la responsabilidad en que podrán incurrir, conforme a las normas que expresamente se citan en la presente Circular [se refiere a la LPHE], cuantas personas, físicas o jurídicas, realicen tales actividades [el uso de detectores de metal en yacimientos arqueológicos] sin la preceptiva autorización oficial". Desde entonces son frecuentes los cursos dedicados a los miembros del SEPRONA sobre actuaciones ilícitas sobre el patrimonio arqueológico.

Por otra parte, como norma, una estadística debería reflejar las diferencias entre una población de datos homogéneos y, en este caso, no lo son. Me explico. No parece coherente comparar comunidades uniprovinciales como Madrid o Murcia con otras pluriprovinciales, caso de Andalucía, con una extensión de casi un tercio de tóda la Península Ibérica, sin aplicar coeficientes de corrección; o, siguiendo esta misma línea, poner en el mismo saco zonas donde la inmensa mayoría del suelo rústico está arado-y por tanto la actividad del buscador es más factible- con otras, como Galicia, Asturias o Cantabria, con una cobertura vegetal estable que dificulta el detectorismo. En conclusión, tomando en cuenta los datos brutos de denuncias del 
SEPRONA, no cabe concluir la abismal distancia entre el expolio en Andalucía y el resto de comunidades del Estado español como se ha hecho, sin que esta observación deba entenderse como negación de que efectivamente esta comunidad autónoma sufre un alto índice de expolio.

La respuesta de la Consejería de Cultura de la Junta de Andalucía ante las denuncias de actividades de los detectoristas, presentadas sobre todo por el SEPRONA y, en menor medida, por las policías locales y la policía judicial, ha variado en el curso del tiempo, pero hasta la fecha se ha concentrado en la instrucción de expedientes sancionadores a quienes han sido sorprendidos con detectores de metal en yacimientos arqueológicos. En este proceso ha sido crucial la promulgación de la Ley 1/1991, de Patrimonio Histórico de Andalucía.

La lentitud de esta respuesta y lo menguado de sus resultados, a primera vista, hà provocado la desesperación entre quienes tienen conocimiento, de forma más o menos directa, de las piezas traficadas ilegalmente en los últimos años. Desesperación que procuran combatir abogando por otras medidas para recuperar esas piezas, como la compra o, al menos, la publicación (Fernández Gómez 1996). Esta postura, esencialmente posibilista, coincide básicamente con la actitud mantenida por muchos países del norte de Europa en relación con los detectores de metal. En el Reino Unido la búsqueda de metales antiguos en yacimientos no está prohibida, aunque existe una conciencia clara del daño que cometen. Sólo se precisa el permiso de la propiedad de los terrenos. No obstante, en Inglaterra, al menos, English Heritage (1991) ha distribuido unas by-laws reguladoras de esta actividad, estableciendo la conveniencia, ampliamente seguida por las casas comercializadoras de estos artefactos, de incluir un libreto en el que se recuerda la prohibición de prospectar en yacimientos protegidos (schedule) a los efectos previstos en la Ancient Monuments and Archaeological Areas Act de 1979. También se recuerda la idoneidad de ofrecer al museo local más cercano aquellos hallazgos más sobresalientes, cuya adquisición, en su caso, se efectúa mediante compra.

Por otra parte, las reglas generales que rigen en los casos de hallazgos casuales en terrenos públicos y privados en el Reino Unido tienen una excepción importante, cuando lo hallado está compuesto por metales preciosos. En este caso, el hallazgo pasa a la Corona. Es la conocida como Ley del Treasure trove. Su origen es medieval, aunque sigue en vigor en el Reino Unido. Se aplica, cada vez con un criterio más restrictivo, a objetos hechos de oro, plata y piedras preciosas. En origen se trataba de una norma destinada a financiar los gastos del gobierno, pero la situación hoy día es bastante distinta: los derechos de la Corona sobre los hallazgos de tesoros, durante los últimos cien años, han sido el medio para proteger piezas de interés para la comunidad y no una fuente de ingresos para el gobierno. Cuando el British Museum desea quedarse con un hallazgo aplicando sobre él el derecho de la Corona, normalmente paga su valor a quien lo ha encontrado.

Debe añadirse que es opinión común entre los juristas (O'Keefe y Prott 1984) que si bien la Common Law inglesa tiene muchos ejemplos de principios y conceptos que permiten adecuar usos originarios de ciertos derechos para afrontar a las nuevas expectativas generadas por la sociedad moderna, en el caso de el treasure trove, los jueces no han sabido adecuarla a las exigencias de una protección de los hallazgos arqueológicos. Esta situación es particularmente preocupante por cuanto que no se ha conseguido crear un régimen jurídico específico para estas situaciones. Por ello la adecuación de la Ley del Treasure trove para otorgar protección a los hallazgos arqueológicos está ampliamente contestada. Teniendo presente que el derecho es sólo sobre los elementos metálicos de oro y plata, su aplicación literal tiende a dividir el hallazgo entre los objetos realizados en metales nobles y el resto. Incluso en el caso Attorney-General of the Duchy of Lancaster v. G.E. Overton (farms) Ltd., de 1980, se realizaron análisis metalográficos para determinar si el contenido de las monedas era plata o una aleación en la que este metal era sólo una pequeña parte, y en razón de ello no estar sujeto el hallazgo al derecho de posesión de la Corona.

Para O'Keefe y Prott, a la vista de la inadecuación de la Ley sobre el Treasure trove, es una pena que el Reino Unido no haya seguido el ejemplo sueco aboliendo la aplicación de esta ley a los restos arqueológicos 
o bien, siguiendo el ejemplo danés, se haya ampliando su contenido para otorgar a los restos arqueológicos una conveniente cobertura jurídica.

Por no extenderme excesivamente en esta divagación, sólo señalaré que para la normativa española, sin embargo, los bienes arqueológicos son de dominio público, situación a la que se ha llegado en ardua disputa con el derecho a la propiedad privada consagrado en el Código civil, proceso que ha corrido de la mano de una profunda revisión del derecho a la propiedad privada en aras a redimensionarlo desde una concepción que parte de su función social (Barrero 1990 y Alegre 1994). No obstante, la consideración demanial de los bienes de carácter arqueológico está continuamente siendo cuestionada en la práctica por los propios jueces: cuando decomisan objetos arqueológicos a buscadores clandestinos o poseedores de colecciones ilegales, devuelven estos bienes ante la presentación de cualquier título de propiedad (factura de compra, por ejemplo), a pesar de ser la imprescriptibilidad una de las características del demanio. También debe tomarse en cuenta que la LPHE ha cambiado el elemento indicador tradicional (la antiguiedad) para determinar la pertenencia de un bien al patrimonio arqueológico, por el de la metodología científica, acreditada por la arqueología, usada en su estudio. Esta definición del patrimonio arqueológico, más acorde con las directrices emanadas de la propia disciplina, tiene efectos jurídicos importantes y novedosos (por ejemplo, en la valoración económica de las piezas arqueológicas expoliadas debería añadirse al propio del objeto el costo de la actividad científica no hecha).

Las vías abiertas por la instrucción de expedientes sancionadores u otras prácticas administrativas (derecho a tanteo y retracto, etcétera..), de un lado, y la postulada por F. Fernández no son ocasionalmente incompatibles, como da a entender este autor, pero la lucha contra el expolio se fortalecería si se siguiesen determinados comportamientos deontológicos entre los profesionales y las instituciones públicas y privadas implicadas siguiesen políticas coherentes con esta problemática, algo que no siempre sucede. Al final de este trabajo, volveré sobre este tema, de momento cabe advertir que, en números absolutos, el monto de expedientes tramitados en Andalucía supera con creces al de las demás comunidades autónomas, según comunicación oral de A. Yáñez, quien está actualmente ultimando un estudio sobre expedientes sancionadores por esta causa en el Estado español entre 1985 y 1995.

\subsection{Los expedientes sancionadores por uso de detectores de metal}

Inicialmente (esto es, desde la asunción de competencias por la Consejería de Cultura en 1984), la mayor parte de las denuncias fueron guardadas sin mayor tramitación. Posteriormente, con la entrada en vigor de la LPHE (1986) se procedió a poner en marcha los expedientes que se habían acumulado. Se estudiaron y clasificaron las denuncias existentes con objeto de abrir, si procedía, expedientes sancionadores. Sin embargo, tanto las remitidas con anterioridad a la entrada en vigor de la LPHE, como la mayoría de las que podían sujetarse al amparo de sus determinaciones, se archivaron al entender que faltaba tipificación de las conductas de los buscadores de restos, por cuanto que si bien la LPHE condena el expolio, no dibuja nítidamente la conducta infractora.

Efectivamente, el artículo 4 LPHE habla de adopción de medidas contra el expolio, que después no tienen reflejo en el artículo 76 LPHE, donde se tipifican las conductas infractoras. En esta misma línea, se interpretaba, por parte de los instructores de expedientes sancionadores, que lo dispuesto en los artículos 41.1 y 41.2 LPHE estaba destinado a someter a previa autorización determinadas prácticas: prospecciones y excavaciones (art. 42 LPHE) cuyo objetivo primario es la investigación, como se deduce de las definiciones que da el legislador de ambas técnicas, consecuentemente lo dispuesto en el artículo 76.1.f, en relación al 42.3 LPHE (esto es, la realización de estas actividades sin autorización), no es aplicable a la conducta de los detectores de metal, al no ser la investigación su objetivo, y su método no asimilable técnicamente a la prospección. 
Igualmente ha tenido incidencia negativa en la resolución de expedientes sancionadores administrativos el hecho de que los denunciantes hayan presentado, ante el órganos judicial correspondiente, denuncia de los hechos, ya que por vía penal el escaso valor de los objetos habitualmente encontrados en posesión de los usuarios de detectores de metal ha propiciado su sobreseimiento. Resuelto el caso penal con esa motivación, el expediente administrativo perdía efecto. Además de ello algunos instructores usaban los mismos argumentos esgrimidos por los jueces para resolver los expedientes administrativos sobreseyéndolos. Con especial frecuencia se aducía el argumento de no estar los terrenos, donde se encontraba el imputado de la acción, declarados como zona arqueológica. Extremo éste que, afortunadamente, ha ido cambiando con el tiempo para adecuarse más a los preceptos de la legislación cultural.

La LPHA, aparecida en 1991, en su artículo 113.5 sí tipifica el uso de detectores de metal como conducta infractora, posibilitando la instrucción de expedientes sancionadores que, además, pasaron a ser competencia de las distintas delegaciones provinciales de la Consejería de Cultura.

Desgraciadamente, debido a la dificultad de acceso a los archivos provinciales no he podido presentar una tabla con el número de denuncias presentadas, cuántas se han convertido en expedientes sancionadores y cuáles han sido sus resultados. Los datos que presento son, pues, necesariamente parciales. Para el periodo 1984-1991, en cifras redondas, encontramos los siguientes supuestos: 350 denuncias, 180 incoaciones e instrucciones, 80 resueltos, bien sancionando bien sobreseyendo. A partir de ese momento, por la imposibilidad ya aludida, sólo he podido manejar expedientes vistos en los servicios centrales en vía de recurso; es decir, aquellos que se han resuelto por las delegaciones provinciales con multas para los imputados y éstos han recurrido ante la Consejería de Cultura. El número total de expedientes vistos por esta vía entre 1992 y 1998 ha sido de 212, obviamente no todos se han resuelto ratificando la resolución recurrida. Significativamente, el Tribunal Superior de Justicia de Andalucía ha fallado favorablemente a las tesis de la Consejería de Cultura los casos vistos por la Sala de lo contencioso administrativo hasta el momento (687/1993, $2538 / 1994,2114 / 1995,2129 / 1995,2301 / 1995,484 / 1996,939 / 1996,940 / 1996$ y 2026/1996, la primera de las cuales se trata de expolio subacuático).

Dada la diferencia de fuentes de información, huelga establecer comparaciones o análisis cuantitativos sobre los expedientes sancionadores instruidos por la Consejería de Cultura entre 1984 y 1999. No obstante, junto a llamativas variaciones provinciales, cuya justificación será posible cuando se haga un estudio de las denuncias emitidas por los cuerpos y fuerzas de seguridad del Estado, quizás lo más interesante de la experiencia acumulada a lo largo de estos años haya sido el desarrollo interpretativo dado a los diversos preceptos sobre los que giran estos expedientes, por cuanto que son perfectamente extrapolables a los nuevos marcos legales surgidos de las leyes autonómicas.

A este respecto, tienen preferencia los obstáculos legales con que se han tropezado los instructores para poder probar que realmente los imputados cometieron la infracción. Para ello, el punto clave, siguiendo con lo expuesto sobre la LPHE, ha sido la cuestión de las pruebas indiciarias. Como ya se ha señalado, muchos expedientes se habían sobreseído alegando los instructores que no existía posibilidad para probar que las personas sorprendidas con detectores de metal tenían la pretensión de encontrar restos. Esta intencionalidad de buscar materiales arqueológicos solamente en contadas ocasiones podría ser objeto de prueba directa y de ahí que, en la mayoría de los expedientes sancionadores incoados por esta causa, se haya acudido a la prueba indiciaria para poder imputar la infracción a los expedientados.

Para entender el valor de este tipo de pruebas debe acudirse a la propia jurisprudencia, por ejemplo la STC 174/1985 sobre el valor de este tipo de pruebas. De acuerdo con ella, la prueba indiciaria ha de partir de unos hechos plenamente probados. De esos hechos, que constituyen los indicios, debe llegarse a través de un proceso mental razonado y acorde con las reglas del criterio humano, a considerar probados los hechos constitutivos de delito o infracción. 
Aplicado al supuesto que comentamos, el hecho de encontrar a un individuo en un lugar determinado provisto de un aparato detector de metales, por sí mismo, no es constitutivo de infracción administrativa, sino simplemente un indicio de que pudiera llegar a concluirse la comisión de la infracción, basado en el nexo causal lógico existente entre el hecho probado y el que se trata de probar, esto es, entre encontrarse en un lugar provisto de un detector de metales y la utilización de estos aparatos con objeto de encontrar objetos arqueológicos sin autorización, máxime si en el lugar de los hechos existe algún yacimiento arqueológico.

Por tanto, si como resultado de la investigación llevada a cabo en un expediente sancionador, resulta probado el hecho de encontrarse el sujeto en un yacimiento con un aparato detector de metales, a partir de ese indicio será lícito concluir que tal aparato estaba siendo utilizado para la búsqueda de restos arqueológicos y será posible imputar la infracción tipificada en la LPHA, con independencia de que el yacimiento en cuestión se encuentre o no inscrito en el Catálogo General del Patrimonio Histórico de Andalucía, o se haya declarado Bien de Interés Cultural, puesto que el precepto mencionado no realiza distinción al respecto. Téngase presente que el patrimonio arqueológico, como sostiene M. R. Alonso (1992), aparece perfectamente identificado e individualizado en la el artículo $40 \mathrm{LPHE}$, de forma que cualquier reconocimiento oficial, no necesariamente expresado a través de un procedimiento administrativo ad hoc, tiene validez para significar la pertenencia de un yacimiento al patrimonio histórico español.

Conectado en cierta forma con esta problemática, también ha sido objeto de reflexión la cuestión sobre qué tipifica como conducta sancionable el artículo 113.5 LPHA (sigo en estos razonamientos el informe de J. M. Maldonado, inédito).

Este precepto considera infracción menos grave "la utilización de aparatos destinados a la detección de restos arqueológicos sin contar con la autorización de la Administración de Cultura o sin cumplir los condicionamientos impuestos en la misma". La tesis mantenida por este autor es que lo prohibido por el legislador andaluz es la actividad (esto es, el uso de un detector de metales), sin que tenga especial significación, a este respecto, la existencia del dolo específico de buscar restos arqueológicos. Se asimilaría este precepto a otros en los que se prohíbe la utilización de cierto tipo de artefactos sin entrar a considerar criterios de intencionalidad. Así, la Ley 4/1989, de 17 de marzo, de Protección de los Espacios Naturales y de la Fauna y Flora Silvestre, prohíbe y sanciona la utilización de métodos masivos y no selectivos de caza, tales como trampas, cepos, lazos, etcétera. No hay en estas infracciones ninguna presunción de culpabilidad como en el caso de los llamados delitos de sospecha, pero ocurre que el aparato no discrimina si lo capturado (odetectado) integra o no el bien protegido. El detector registra lo mismo un objeto perteneciente al patrimonio arqueológico que otro metálico cualquiera; por tanto, para evitar la merma de bienes arqueológicos, se somete a previa autorización su uso y sancionándose a quien no cuenta con ella o incumple los condicionantes de la misma.

Esta interpretación se apoya también en la del artículo 112.4 LPHA, que califica de infracción grave "la realización de actividades arqueológicas sin cumplir los requisitos previstos en el artículo 52 de esta Ley o sin respetar los condicionantes impuestos en las autorizaciones administrativas". Por esta vía se sanciona la realización de actividades arqueológicas sin autorización. Prescindiendo de los elementos negativos que no afectan al núcleo de la cuestión debatida, para que una actividad sea sancionable ha de calificarse como arqueológica. Esta calificación no presentará problemas cuando esté hecha siguiendo la metodología impuesta por esa disciplina; "pero es evidente que con mayor motivo deberá también sancionarse a quien realiza esas actividades de forma burda, sin método, con la intención de buscar restos arqueológicos". Es decir, que si quien está prospectando con un detector de metales lo hace con la intención de buscar restos arqueológicos, comete la infracción tipificada en el artículo 112.4 y no la del 113.5. Si se acepta la tesis, sostenida habitualmente, de precisarse una prueba de intencionalidad (búsqueda de restos arqueológicos) en la aplicación del artículo 113.5, éste resultaría del todo inútil al estar la conducta ya tipificada en el 112.4. 
En definitiva, frente al artículo 112.4 LPHA (asimilable a estos efectos al artículo 76.1.f LPHE, y al 2.b del Decreto 58/1994 de Castilla y León y concordantes en las demás legislaciones autonómicas) en que la finalidad arqueológica se predica de la acción, en el artículo 113.5 LPHA ésta es predicable del aparato, con lo que la infracción se consuma con la mera aplicación del detector de metales, con independencia de la intención del autor. Así, para J. M. Maldonado, el problema planteado por la aplicación del artículo 113.5 LPHA "no es el de si el autor tenía o no la intención de buscar restos arqueológicos, sino el determinar cuáles sean esos aparatos destinados a la detección de restos arqueológicos", cuyo uso queda sujeto a previa autorización administrativa. Para el precepto antes señalado de la legislación medio ambiental, la administración ha solventado las dudas realizando una enumeración de los instrumentos de caza prohibidos en el RD 1095/1989, de 8 de septiembre. No existe nada similar para la normativa de protección del patrimonio histórico. Éste sería el colofón que completaría la normativa andaluza en este sentido.

Estas reflexiones dieron como consecuencia un estudio sobre la cuestión por parte del Servicio de Asuntos Jurídicos de la Consejería de Cultura, en el que se desestimaba esta interpretación por no adaptarse a la normativa vigente actualmente aplicable.

Se entiende que presenta determinados problemas en orden a la seguridad jurídica que debe presidir la actuación administrativa, concretada en este caso en la cuestión de la tipicidad de la conducta infractora.

La argumentación se sustenta sobre el hecho de que los detectores de metal no sólo sirven para anunciar la presencia de restos arqueológicos, sino que tienen otros muchas aplicaciones, con lo cual es preciso la concurrencia del instrumento adecuado y el lugar idóneo, esto es, que se haga en un yacimiento arqueológico, para que exista -en razón de su competencia-causa para la intervención de la Consejería de Cultura. Desde este punto de vista, la LPHA sanciona la realización de la actividad arqueológica y no la mera intencionalidad, aunque para llegar a la convicción de que se ha consumado la actividad, mediante pruebas indiciarias, no sea ajena la intencionalidad del autor.

En lo referido a la duplicidad de artículos para la sanción de prospecciones arqueológicas con detectores de metal, se razona que la intención del legislador ha sido sacar de las sanciones consideradas graves el empleo de los detectores de metal, incluyéndolo, por tanto, en el 113.5 LPHA. En aras de un principio de tipicidad y especificidad, éste sería el artículo de aplicación en estos supuestos y no el más genérico (112.4 LPHA).

A pesar de la contundencia de la argumentación de los servicios centrales de la Consejería, las reflexiones planteadas por J. M. Maldonado son sumamente sugestivas y, evidentemente, producirían un mayor rendimiento en la instrucción de expedientes sancionadores por utilización de detectores de metal. Sobre el debate abierto en Andalucía, parece determinante la posibilidad de uso de estos aparatos distinto de la detección de objetos metálicos arqueológicos. A este respecto, me gustaría apuntar una observación más.

Con independencia de las ocasionales aplicaciones en que puedan emplearse estos aparatos, la propaganda hecha por sus fabricantes, aunque eviten mencionar términos directamente relacionados con el patrimonio histórico (antigüedades, etcétera) está indudablemente dirigida hacia esta actividad disfrazada de "entretenido hobby de buscar toda clase de tesoros metálicos con un moderno detector de metales" (sacado del folleto publicitario de la marca COMPASS). En otros casos los aparatos poseen ingenios especiales para encontrar alteraciones del terreno de carácter arqueológico, como el modelo TM 808 de la casa White's, especialmente diseñado para la búsqueda de objetos metálicos grandes (pucheros llenos de monedas, balas de cañón, rifles, espadas...), que lleva incorporada una función especial para "buscar cuevas, huecos, pozos y túneles; sitios populares para esconder objetos". El prospecto continúa aclarando que "Muchos objetos han sido escondidos en cuevas, o enterrados profundamente para evitar el hallazgo de su contenido". En ocasiones la relación con la práctica de excavaciones arqueológicas se plantea claramente, a pesar de no mencionarlas. Por ejemplo, en el relato de un experto detectorista estadounidense que acompaña la propaganda del modelo XLT de la marca Spectrum, "Hace poco-cuenta E. Fedory-salimos a buscar reliquias y nos acercamos hasta un pueblo que había sido abandonado recientemente. Encontramos una serie de reliquias muy interesantes de finales 
del siglo XVIII y principios del XIX. Encontramos monedas de cobre y plata, cabezas de hacha y utensilios primitivos, municiones de mosquetes y antiguos misiles. Una excursión divertida con buenos resultados".

En España los distribuidores de detectores de metal suelen incluir, entre los folletos dados con la compra de uno de estos aparatos, una tarjetita con un código ético del detectorista, en el que se le precave de las responsabilidades en que puéde incurrir si daña bienes integrantes del patrimonio histórico, entre otras consideraciones, pero se limita a incluir entre éstos exclusivamente los yacimientos declarados como zonas arqueológicas, no advirtiendo, por tanto, de las limitaciones reales impuestas por la legislación sobre patrimonio histórico, que a la postre incapacitan el uso del aparato para la principal función que ha sido diseñado, reduciendo su uso a lugares donde puedan aparecer objetos perdidos contemporáneamente (playas, por ejemplo) o parajes en que no existan restos arqueológicos, con lo cual probablemente no encuentren absolutamente nada.

Debe tomarse en consideración la diferencia en torno al concepto de propiedad privada existente entre los países fabricantes de estos aparatos (fundamentalmente Estados Unidos) y España, y el nuevo concepto de patrimonio arqueológico incorporado a la legislación española, aspectos ya mencionados.

En definitiva, los detectores de metal están diseñados originariamente por sus fabricantes para la búsqueda de objetos metálicos antiguos enterrados, esto es, bienes pertenecientes al patrimonio arqueológico. Su eventual empleo en otras actividades no los desnaturaliza, al igual que una llave seguirá sirviendo principalmente para abrir y cerrar cerraduras, aun cuando pueda aplicarse como abridor de botellas de cerveza.

Aunque pueda parecer que se trata de una casuística referida concretamente a la comunidad autónoma de Andalucía, sin embargo no es así. En mi opinión a esta misma controversia se llegaría aplicando la mayoría de las leyes autonómicas. Algunos ejemplos, aparte del Decreto de Castilla y León mencionado y la propia LPHE, pueden àclarar esta aseveración.

El artículo 17 de la 4/1990 de Patrimonio Histórico de Castilla-La Mancha ("La realización de excavaciones o prospecciones en terrenos de valor arqueológico de Castilla-La mancha que carezca del oportuno permiso y que se realicen con el fin de obtener cualquier tipo de resto arqueológico serán ilícitas y sancionadas conforme a lo dispuesto en la presente Ley. Se incluye en este concepto la utilización de cualquier aparato cuyo funcionamiento esté encaminado a la obtención de restos arqueológicos...". Para más inri el régimen sancionador al que se remite es el de la LPHE). Desde una interpretación literal de esta ley autonómica y la LPHE a la que se remite, este artículo no resuelve el problema de tipificar la conducta infractora de los detectoristas al seguir asimilando esta actividad con la prospección. En puridad la ley castellano-manchega añade un supuesto perfectamente inútil (la prospección con detector de metales) al ya estar incluido en el concepto de prospección, que no excluye el uso de instrumentos auxiliares para la inspección superficial.

De otro lado, los artículos 91.k) y 93.c) de la Ley 8/1995, de Patrimonio Cultural de Galicia, que consideran respectivamente infracción grave la realización de actividades arqueológicas sin la correspondiente autorización y leve, grave o muy grave, en función de daño ocasionado, la utilización sin la debida autorización "sistemas, técnicas y métodos de detección de bienes integrantes del patrimonio cultural, tanto en el suelo como en el subsuelo...", si bien matizan perfectamente la cuestión de la duplicidad de artículos mediante la aplicación del principio de la especificidad, el segundo de ellos parece perseguir el empleo del aparato sin la autorización correspondiente.

Así mismo, el artículo 78.2 de la Ley 11/1998 de Patrimonio Cultural de Cantabria (por el que se prohíbe el uso de detectores de metales y aparatos de tecnología similar fuera de las actuaciones legalmente autorizadas) podría entenderse por esta misma vía, refrendada por el artículo 130.j) de esta norma, que declara infracción grave "La utilización de detectores de metales o aparatos de tecnología similar en actuaciones arqueológicas ilícitas o no expresamente autorizadas por la Consejería de Cultura y Deportes. No obstante, esta norma matiza la prohibición genérica del aparato, aludiendo expresamente a su uso dentro de actividades arqueológicas. 
En contra, sin embargo, estaría el artículo 44 de la Ley 10/1998 de Patrimonio Histórico de la Comunidad de Madrid ("Se prohíbe el uso de detectores de metales y otros instrumentos similares en el ámbito de los bienes integrantes del patrimonio Histórico de la Comunidad de Madrid, salvo autorización de la Consejería de Educación y Cultura, exclusivamente con fines de educación y seguridad"), que delimita perfectamente el ámbito espacial de uso en que estaría prohibido el uso del aparato sin autorización.

En general se aprecia una identificación del empleo de los detectores de metales y otros aparatos semejantes con la actividad de prospección, cuando quizás lo más interesante sería -como ya se ha señalado-intentar la prohibición del uso de estas herramientas sin autorización previa, ya que con independencia de su aplicación a ciertos supuestos que no afectan a la integridad del patrimonio arqueológico, están especialmente diseñados para encontrar objetos metálicos enterrados que, en una inmensa mayoría, suelen ser bienes arqueológicos. Además, el aparato no distingue si se tata de un bien arqueológico o no, con lo cual podría estar sujeto a una cautela análoga a la vista para los artilugios de caza que no discriminan. Estos extremos, evidentemente, no han pesado en la mente del legislador, aunque la falta de criterios permite ciertas interpretaciones más o menos favorables a esta tesis. Mientras tanto, como reconocía el informe antes aludido de la Consejería de Cultura, el valor de la prueba indiciaria será determinante.

Por otra parte, la normativa internacional podría interpretarse desde una aproximación tendente a controlar el uso de esos aparatos, al margen de las actividades de prospección.

Así la citada Directiva 921, señala en su recomendación 14.ii) que se considere la adopción de recomendaciones a los gobiernos para "instituir un sistema de licencias o registro de usuarios de detectores de metales".

La Convención de Malta (1992) en su artículo $3^{\circ}$, prevé con el fin de preservar el patrimonio arqueológico y para garantizar el carácter científico de las actividades de investigación arqueológica, que cada país se comprometa a:

“i) poner a punto procedimientos de autorización y de control de las excavaciones y de otras actividades arqueológicas, con el fin de:

a) prevenir cualquier excavación o desplazamiento ilegal de elementos del patrimonio arqueológico.

b) asegurar que las excavaciones y prospecciones arqueológicas se abordan de forma científica y cuidando de que:

- los métodos de investigación no destructivos se empleen tanto como sea posible;

- los elementos del patrimonio arqueológico no sean extraídos durante las excavaciones ni dejados

al aire libre durante o después de las mismas, sin que se hayan tomado las medidas convenientes para su preservación, su conservación y su gestión;

ii) velar para que las excavaciones y otras técnicas potencialmente destructivas no sean practicadas más que por personas cualificadas y especialmente habilitadas.

iii) someter a autorización previa específica en los casos previstos por la legislación interna de cada Estado, el empleo de detectores de metales y de otros equipos de detección".

Con lo cual delimita perfectamente la cuestión referida a la práctica adecuada de las prospecciones arqueológicas y, como caso distinto el asunto de los detectores de metal y aparatos análogos.

Con respecto de esta Convención, cabe señalar que el tono "más débil del que a muchos les hubiese gustado ver" adoptado por ella al tratar el tema concreto de los detectores de metal es considerado una de las lagunas más llamativas del documento (Cleere 1998: 401).

En todo caso, queda abierta esta consideración sobre la posibilidad de sometimiento a regulación, como ocurre con las escopetas de caza, de estos aparatos, controlando su venta y utilización, actualmente enteramente libre, como se concluye de un informe jurídico sobre la licitud de los detectores de metal y su aplicación, encargado por la Asociación Española de Detectoristas y publicado en el número 10(1994) de El Buscador, tras consultar al Servicio de Explotación y Seguridad Minera del Ministerio de Industria y Energía (1985), a la Dirección de Seguridad del Estado (1993) y a la Jefatura de la $112^{a}$ Comandancia de la Guardia Civil de Tres Cantos (Madrid) (1993). 


\subsection{Otras actuaciones contra el expolio arqueológico}

El Plan General de Bienes Culturales de la Consejería de Cultura vigente entre 1989 y 1995 (Consejería de Cultura 1993) no tomaba en consideración, de forma individualizada, el expolio arqueológico, integrando las actuaciones contra el mismo dentro de la protección del patrimonio histórico, cuya principal preocupación era organizar e institucionalizar la elaboración de catálogos e inventarios de yacimientos arqueológicos, así como las declaraciones a efectos de la LPHE y LPHA. Esta labor devino en una de las principales actividades desplegadas por la Consejería, como muestran las memorias de gestión de los arqueólogos provinciales publicadas en los Anuarios Arqueológicos de Andalucía.

No obstante, a su amparo se desarrollaron todas las actuaciones sancionadoras descritas anteriormente, se impartieron en prácticamente todas las provincias, cursos divulgativos y de información a los cuerpos y fuerzas de seguridad -aunque no con la periodicidad requerida por la frecuente renovación de la plantilla de esos cuerpos-, y apareció la LPHA, que presta especial atención a esta problemática.

El nuevo Plan General de Bienes Culturales 1996-2000, sí ha considerado conveniente incluir entre las líneas de actuación del programa de protección, una específicamente dirigida a la lucha contra el expolio de yacimientos arqueológicos (Consejería de Cultura 1997: 126). Sus objetivos se cifran en varios campos: - Evaluación y unificación de criterios en aquellos órganos e instituciones implicados en la lucha contra el expolio, o directamente relacionados con él (Consejería de Cultura, Ministerios de Educación y Cultura, jueces, fiscales, Guardia Civil, Policía Judicial, coleccionistas y anticuarios...).

- Redacción de normas y directrices que permitan tipificar las faltas y delitos por conductas expoliadoras.

- Formación y sensibilización en materia de lucha contra el expolio dirigida hacia los cuerpos y fuerzas de seguridad del Estado, especialmente la Brigada de Patrimonio de la policía judicial y el SEPRONA de la Guardia Civil.

- Proteger yacimientos con amplio historial de expoliación con actuaciones directas de protección física.

Para ello se dispone una serie de medidas destinadas a propiciar los objetivos antes señalados:

- Reuniones sectoriales y generales entre los órganos e instituciones antes señalados con objeto de tener una valoración conjunta de la situación.

- Regulación del uso de detectores de metal siguiendo el modelo del Reglamento de Armas de Fuego. - Cursos de especialización y acercamiento a la arqueología para los miembros del la Brigada de Patrimonio y del SEPRONA. Elaboración de un cuaderno con las normativas de aplicación y los procedimientos a seguir en caso de expolio.

- Diseño de campañas explicativas en colegios y ayuntamientos sobre los daños que provoca el expolio. - Actuar con los colegios en la protección física de yacimientos sembrándolos de virutas metálicas, no discriminadas por los detectores de metal.

- Diseño de medidas que incentiven la regularización de colecciones cuyo origen no se ajuste a las previsiones de la legislación vigente.

Así como proyectos concretos:

- Mesa de trabajo sobre el expolio coordinada por la Consejería de Cultura.

- Redacción del reglamento de uso de detectores de metal en yacimientos arqueológicos.

- Curso de formación para cuerpos y fuerzas de seguridad del Estado.

- Redacción de un cuaderno sobre el expolio para uso de los miembros de los cuerpos y fuerzas de seguridad del Estado.

- Proyecto de difusión y protección activa del patrimonio arqueológico, en colegios y ayuntamientos de Andalucía. 
Las medidas y actuaciones dirigidas a la coordinación con las demás instituciones y organismos implicados en la lucha contra el expolio no requieren mayor explicación, pues se han convertido en una práctica (o deseo) habitual en la mayoría de las comunidades autónomas. Otro tanto puede decirse de aquéllas destinadas al perfeccionamiento de la capacitación de los agentes de la policía judicial y del SEPRONA para esta tarea. Sobre la intención de regular la distribución de los detectores de metal, ya se ha visto por dónde se mueve el debate jurídico, aunque deba reconocerse que éste no partió como desarrollo del Plan General, sino desde la experiencia en la instrucción de expedientes sancionadores. Sí debe explicarse la medida dirigida a la protección física de los yacimientos arqueológicos con antecedentes de expolio significativo, consistente en el "sembrado de virutas metálicas", por cuanto que pueda parecer anecdótico o no sea fácil de comprender.

En los casos de yacimientos con amplio historial de expolio, donde además por sus especiales condiciones sean eficaces estas medidas (como en Cueva Ambrosio o la Cueva de la Carigüela), se han adoptado determinadas medidas de protección física consistentes principalmente en poner puertas a la entrada de las cuevas, aunque las continuas denuncias sobre excavaciones clandestinas en ellas, muestran que no resultan tan definitivas como sería de desear. Por otro lado, salvo aquéllos propiedad de la Junta de Andalucía que cuenten con servicios de guardería, que lógicamente son muy pocos, resulta poco viable vallar los yacimientos, aún en el supuesto de que sus propietarios estuviesen de acuerdo, con objeto de impedir su expolio. Tal propuesta dificultaría, en una gran mayoría de casos, su aprovechamiento agrícola y, por otra parte, este tipo de protecciones físicas no suponen obstáculos serios para los expoliadores, antes bien se les facilitaría la identificación de los yacimientos.

Así las cosas, contrariamente a lo que parece, la propuesta reflejada en el Plan General de Bienes Culturales no está dirigida a dificultar la detección de metales, normalmente estos aparatos están provistos de discriminadores que evitan ese tipo de interferencias, sino que su objetivo es impedir el hallazgo de tumbas. Como ya se dijo anteriormente, para este menester también se usan los detectores de metal, siendo así que los nuevos modelos, como el TM 808, permite profundizar hasta $215 \mathrm{~m}$, para detectar objetos con una capacidad de 15 litros. A este respecto se ha observado que un nuevo tipo de abono sacado de reciclar residuos sólidos urbanos (un tipo de compost), rico en detritos metálicos, dificulta la detección no de metales, sino del material constructivo empleado en las estructuras funerarias. El empleo sistemático del discriminador, a que obliga la presencia de pequeños fragmentos metálicos de tamaño y naturaleza diversa, amortigua el tono base del aparato hasta una frecuencia que apenas permite el contraste.

Esta práctica ya ha sido aplicada en diversos lugares de nuestra comunidad. En Galera, por ejemplo, profesores de EGB organizaron patrullas de estudiantes que durante los fines de semana esparcían chapas de botellas, recolectadas en los bares, en los yacimientos arqueológicos con el propósito de intentar despistar a los detectoristas. También se ha probado con fragmentos de imanes, que bloquean las agujas de los aparatos menos sofisticados. Otras iniciativas similares han tenido lugar en localidades como Osuna (Sevilla), sometidas a expolios intensivos con diversa efectividad, especialmente porque han carecido de continuidad.

El propósito del Plan General era precisamente recoger lo positivo de estas iniciativas y encauzarlas a través de campañas que involucrasen a la población escolar para que, además, sirviesen como medio de sensibilizarlos sobre la pérdida irreparable derivada de la acción de los expoliadores.

Por razones que no hacen al caso, el Plan General de Bienes Culturales 1996-2000 ha tenido una tramitación excesivamente larga, con lo cual muy poco de lo dispuesto en él ha podido activarse. Entre ellas no está esta iniciativa. No obstante, la lucha contra el expolio es una línea de actuación de la administración que trasciende los periodos de vigencia de los planes, por lo que siempre se está a tiempo de avanzar por estos caminos.

En esta misma situación se encuentran determinadas disposiciones recogidas en la legislación sobre patrimonio histórico, cuya puesta en práctica ayudaría bastante en la persecución del comercio ilícito. Es el caso de la obligación de las personas y entidades dedicadas al comercio de bienes muebles de carácter cultural (anticuarios, marchantes y casas de subastas, entre otros), de llevar un libro de registro en el que 
anotar todas las transacciones de bienes inscritos en el Catálogo General del Patrimonio Histórico Andaluz y, en todo caso, superiores a cincuenta años de antigüedad. Este libro de registro habría de seguir un modelo oficial aprobado por la Consejería de Cultura (artículos 46 LPHA y 67 a 71 del Reglamento de Protección y Fomento del Patrimonio Histórico de Andalucía de 1995).

\section{LA DIFUSIÓN DEL PATRIMONIO ARQUEOLÓGICO COMO INSTRUMENTO DE PREVENCIÓN}

Existe una lógica coincidencia entre quienes se enfrentan a la cuestión del expolio en abogar por medios educativos y de sensibilización social como inversión más segura, a medio y corto plazo, para erradicar en gran medida tanto las propias conductas expoliadoras como la indiferencia social hacia la sangría del patrimonio arqueológico que conlleva.

La Recomendación 921 del Consejo de Europa dice en su sexto considerando “Alegrándose del interés del público en la arqueología, pero deseando fomentar el interés a través de un grado de involucración superior de un público responsable en arqueología y una mejor apreciación de las evidencias que la investigación arqueológica puede revelar" para proponer, seguidamente entre otras cosas, que se lance una campaña informativa sobre arqueología, coordinada por el Consejo de Europa, dirigida al público en general, a los gobiernos y a los comerciantes de detectores de metales y antigüedades, así como que se apoye la inclusión de una introducción a la arqueología en la educación escolar, como parte de los estudios de historia, para así fomentar una actitud más responsable hacia los vestigios del pasado.

Por su parte, la Convención de Malta prevé el compromiso de los miembros firmantes de la misma para emprender una acción educativa destinada a despertar y desarrollar en la opinión pública una conciencia sobre el valor del patrimonio arqueológico para el conocimiento del pasado, y sobre los peligros que amenazan a este patrimonio; así como para promover el acceso del público a los elementos principales de su patrimonio arqueológico, sobre todo a los yacimientos arqueológicos, y a apoyar la exposición al público de los bienes arqueológicos seleccionados.

Como han expresado con acierto M. A. Querol y B. Martínez (1996: 252) "la verdadera lucha contra estas intervenciones clandestinas, en algunas regiones mucho mayores en número e incidencia que las autorizadas, pasa a la fuerza por una inversión a largo plazo ante la que las Administraciones competentes parecen remisas: la modificación de los curricula educativos con la introducción de nociones sobre la existencia, el verdadero valor, el posible tratamiento y el significado del patrimonio arqueológico".

No obstante, a pesar de todas estas advertencias y recomendaciones, no siempre existe en el ámbito de la difusión una postura coherente que secunde la labor de lucha contra el expolio desarrollada por la propia administración. Es como si lo hecho con una mano, a veces, se deshiciese con la otra.

Muchísimos museos arqueológicos todavía siguen aferrados a un discurso centrado en las piezas, siguiendo un paradigma científico, actualmente desfasado, que apenas da importancia al relato histórico contextualizador de los objetos comunes y artísticos o a los procesos de conocimiento y cambio social, prefiriendo llamar la atención del público sobre piezas insólitas por su rareza o calidad artística. Lógicamente, desde estos presupuestos conceptuales se exacerba aún más el sentimiento de frustración cuando "las piezas buenas" salen al extranjero. Tampoco animan a dar algún valor a las respuestas internacionales, arbitradas desde círculos profesionales de la museística, para tratar de frenar el comercio ilícito de objetos arqueológicos. Resulta obvia la retroalimentación que ese discurso "arqueográfico" (Alcina 1975) ha venido haciendo del gusto anticuarista por atesorar bienes poco frecuentes, en colecciones ya sean privadas o públicas (Ruiz, Molinos y Hornos 1986). 
Los efectos de la obsolescencia en la presentación de las colecciones de muchas instituciones museísticas se dejan rápidamente sentir en los nuevos museos locales que han ido surgiendo en los últimos años, al seguir los patrones de los provinciales de mostrar piezas esperando que éstas por sí mismas transmitan el mensaje que quienes las han situado no sabían construir. En los museos locales, la situación es doblemente negativa: a la sustitución del relato por el objeto se une, además, que estas instituciones suelen partir de colecciones fundacionales constituidas por materiales expoliados por vecinos que, mediante la donación o depósito de todo lo que no pueden vender, pasan a ser considerados como benefactores de la cultura local. Caso paradigmático ha sido el Museo de Historia Local de Écija (Sevilla). En su primer montaje despreciaba años de investigación histórica y arqueológica realizados en esta ciudad, en aras de mostrar un batiburrillo de objetos procedentes de expolios, pero que a diferencia de los recogidos en las excavaciones urbanas estaban enteros o eran raros, con la obtusa idea de servir de reclamo a paisanos y turistas (Rodríguez Temiño en prensa). A raíz de las críticas recibidas las autoridades municipales decidieron cambiar de estrategia y, en lugar de despilfarrar el presupuesto comprando colecciones particulares, se encargó a una empresa de arqueólogos profesionales la elaboración de un proyecto museológico nuevo, que ha corregido -al menos en parte- los dislates iniciales.

Las exposiciones temporales, actividad actualmente privilegiada en el campo de la difusión, deberían tener una incidencia enorme en este proceso educativo y de concienciación, habida cuenta del éxito de público que concitan. Desgraciadamente, las dedicadas al patrimonio arqueológico frecuentemente sólo innovan en los recursos museográficos-esto es, en la presentación de las piezas-, pero el discurso positivista en torno al objeto sigue siendo igual de rancio que hace décadas. Serían muchos los ejemplos que podrían aducirse a este respecto, pero por su especial énfasis en el expolio, y para ilustrar las dos caras de la moneda, me ceñiré a dos casos recientes, que además fueron casi simultáneas aunque en ciudades distintas (Rodríguez Temiño 1998).

En Sevilla (1998) se mostraba una exposición titulada Egipto milenario. Vida cotidiana en la época de los faraones (que posteriormente pasearía por otras ciudades españolas) en la que pretendía, como su nombre indica, dar una visión sobre aspectos menos conocidos del antiguo Egipto, a través de una colección de objetos artesanales de uso habitual en ese tiempo procedentes de los fondos del Roemer und Pelizaeus Museum de Hildesheim (Alemania).

La puesta en escena era realmente exquisita, con vitrinas diseñadas especialmente para que los efectos de luz resaltasen las piezas y otros recursos al uso. Sin embargo, es la típica exposición en que las piezas arqueológicas son un mero adorno de un discurso basado fundamentalmente en el conocimiento transmitido por los textos. La arqueología se retrotrae, contrariamente a lo que se sugería en el video inicial, a la época en que se identificaba con la anticuaria, es decir, con el coleccionismo de objetos. La organización del ejército o el panteón de dioses egipcios -por poner dos de los temas tratados-se ilustraban con determinados artefactos, pero la información dada de ellos no se deducía de los objetos mostrados; incluso se había omitido poner de manifiesto las relaciones entre las distintas facetas sociales y económicas de esa sociedad, proceso lógico cuando se pretende dar una idea global de cualquier comunidad humana, y argumento imprescindible en la investigación arqueológica (Egipto milenario... 1998).

Supongo que no será baladí para entender esta aproximación a la función de la arqueología en el conocimiento sobre las sociedades antiguas, saber que la totalidad de las piezas mostradas son producto de expolio, aunque sea del siglo pasado, como demuestra la ignorancia de los lugares de procedencia de las piezas. Quizás lo más lamentable de este caso sea que, por ningún medio, se hiciese mención de esta circunstancia, con lo cual la exposición perdía un plus de interés al haber podido entroncar con una problemática actual, y unir a la información de los objetos su propio discurso como colección.

Por contra, en esas mismas fechas por Granada y Jaén itineraba la muestra Hace 4000 años ..., basada en el proyecto de investigación de dos poblados prehistóricos de ambas provincias desarrollado por la Universidad de Granada. En ella, la arqueología se expone desde una perspectiva científica, como una 
disciplina destinada a reintegrarnos el conocimiento de nuestro pasado a través del estudio de la cultura material y la evidencia medio ambiental. Dedicaba, por tanto, especial relevancia a la metodología usada en el registro arqueológico y su conversión en historia, a la vez que daba información sobre los modos de vida de las sociedades analizadas. Discursos apoyados con la documentación gráfica y los objetos materiales que componen la propia exposición.

Aunque no se aludía explícitamente, se hacía patente la distinción entre registro de la evidencia arqueológica y la posterior elaboración de la memoria colectiva, que es historia e interpretación a partir de ella, y depredación de un yacimiento mediante la rebusca de objetos en la que todo este caudal informativo se pierde irremisiblemente.

Por último, habría que mencionar la actual consolidación de un movimiento de concienciación internacional sobre los perjuicios ocasionados a los países tradicionalmente expoliados por el tráfico ilícito de antigüedades. Obviamente, esto no es nuevo, pero la novedad es que ahora está auspiciado por los más importantes museos de los países tradicionalmente compradores. Su acta de nacimiento fue la Declaración de Berlín, aprobada en 1988 por iniciativa especial del profesor Heilmeyer, director del Antikenmuseum de Berlín (Pallottino 1992). En esta declaración las grandes instituciones museísticas reconocen la prioridad del valor científico de objetos arqueológicos y adquieren el compromiso de rechazar cualquier pieza de la que se desconozca la procedencia, como contribución en la lucha para frenar esta lacra.

Lógicamente éste no puede ser el único recurso, pero su consolidación reforzará las normativas estatales e internacionales represoras del expolio y el comercio ilícito de antigüedades. $\mathrm{O}$, al menos, eso espero.

\section{BIBLIOGRAFÍA}

ALCINA, J. (1975): "La arqueología antropológica en España: situación y perspectivas", I Reunión de Antropólogos Españoles (Sevilla, 1973), Sevilla: 47-62.

ALEGRE, J. M. (1994): Evolución y régimen jurídico del Patrimonio Histórico, Ministerio de Cultura, Madrid, (2 vol.).

ALONSO, M. R. (1992): El patrimonio histórico. Destino público y valor cultural, Civitas, Madrid.

BARRERO, C. (1990): La ordenación jurídica del Patrimonio Histórico, Civitas, Madrid.

BENÍTEZ DE LUGO, L. y SÁNCHEZ-SIERRA, A. E. (1995): "El furtivismo arqueológico. Consideraciones legales y científicas sobre los hallazgos arqueológicos", Boletín Informativo 12, (Instituto Andaluz de Patrimonio Histórico): 38-43.

CABALLERO, L. (1982): "Los detectores de metal", Revista de Arqueología 17: 28 y s.

CLEERE, H. (1998): "Managing the archaeological heritage", Antiquity 67: 400-402.

CONSEJERÍA DE CULTURA, JUNTA DE ANDALUCÍA (1993): Plan General de Bienes Culturales, Sevilla.

(1997): Plan General de Bienes Culturales de Andalucía. 1996-2000, Sevilla.

Curso: Protección del patrimonio arqueológico, dirigido a los cuerpos y fuerzas de seguridad del Estado, (Murcia, 1994), Región de Murcia, Murcia 1996.

DURÁN, V. (1984): La batalla de Munda, Córdoba.

DURÁN, V. y FERREIRO, M. (1984): “Acerca del lugar donde se dio la batalla de Munda", Habis 15: 229-236.

Egipto Milenario. Vida cotidiana en la época de los faraones, Catálogo de la exposición, Fundación "la Caixa", Barcelona, 1998.

ENGLISH HERITAGE (1991): Exploring our Past. Strategies for the Archaeology of England, English Heritage, Londres. 
FERNÁNDEZ GÓMEZ,F. (1996): "De excavaciones clandestinas, mercado de antigüedades y publicación de 'hallazgos'", en M. A. Querol y T. Chapa (eds.): Homenaje al Profesor Manuel Fernández-Miranda, Complutum Extra, 6 (II): 283-294.

Hace 4000 años... Vida y muerte en dos poblados de la alta Andalucía, Catálogo de la Exposición, Consejería de Cultura de la Junta de Andalucía, Fundación Caja Granada y Universidad de Granada, Garanda 1997.

INIESTA, Á. (1996): "Los daños sobre el patrimonio arqueológico: actividades que los generan y actuación policial sobre el terreno", en Curso: Protección del patrimonio arqueológico, dirigido a los cuerpos y fuerzas de seguridad del Estado, (Murcia, 1994), Región de Murcia, Murcia: 65-100.

MALDONADO, J. M. (inédito): "Informe sobre la interpretación del artículo 113.5 de la Ley 1/1991", Delegación Provincial de Córdoba de la Consejería de Cultura, 1998.

O'KEEFE, P. J. y PROTT, L. V. (1984): Law and the cultural heritage. Discovery and excavation, vol. I, Professional Books Limited, Oxford.

PALlOTTINO, M. (1992): "Beni archeologici in Europa (Tavola rotonda, intervento conclusivo). Risoluzioni", Eutopia 1: 113-117.

Protección del patrimonio histórico. La Guardia Civil y la conservación de los bienes culturales, (Ávila, 1997), Junta de Castilla y León y Guardia Civil, Valladolid, 1998.

QUEROL, M. A. y MARTÍNEZ DÍAZ, B. (1996): La gestión del Patrimonio Arqueológico en España, Alianza Editorial, Madrid.

RODRÍGUEZ TEMIÑO, I. (1998): "Exposiciones de arqueología y expolio", El Correo de Andalucía de 24 de febrero.

_- (en prensa): "La gestión del patrimonio arqueológico en Écija”, V Congreso de Historia de Écija (Écija, 1998), Ayuntamiento de Écija y Universidad de Sevilla.

RUIZ RODRÍGUEZ, A.; MOLINOS, M. y HORNOS, F. (1986): Arqueología en Jaén (Reflexiones desde un proyecto arqueológico no inocente), Diputación Provincial de Jaén, Jaén.

SÁNCHEZ ARROYO, J. A. (1998): "Expolio Arqueológico", Protección del patrimonio histórico. La Guardia Civily la conservación de los bienes culturales, (Ávila, 1997), Junta de Castilla y León y Guardia Civil, Valladolid: 137-146. 